\title{
Development of sensitivity to information for impending collision
}

\author{
ALBERT YONAS, A. GORDON BECHTOLD, DANIEL FRANKEL, F. ROBERT GORDON, \\ GERALD McROBERTS, ANTHONY NORCIA, and SUSAN STERNFELS \\ Institute of Child Development, University of Minnesota, Minneapolis, Minnesota 55455
}

\begin{abstract}
Infants were tested in three experiments to study the development of sensitivity to information for impending collision and to investigate the hypothesis that postural changes of very young infants in response to an approaching object are of a tracking rather than of a defensive nature. Experiment 1 involved the presentation of three types of shadow projection displays, specifying (1) collision, (2) noncollision, and (3) a nonexpanding rising contour, to infants from 1 to 9 months of age. Avoidance of collision appears to be absent in 1. to 2-month-olds, begins to develop in 4 - to 6-month-olds, and is present in 8- to 9-month-old infants. In Experiment 2, 1- to 2-month-old infants were presented with optical expansion patterns which specified collision and noncollision. The top contour of these displays stayed at eye level. No significant difference was observed between reaction to the collision and the noncollision displays, suggesting that the young infants were tracking the displays and not attempting to avoid collision. Experiment 3 was designed to determine whether an approaching real object might elicit an avoidance response in infants not sensitive to an optical display specifying collision. No evidence of avoidance behavior was observed in the 1-to 2-month-olds; however, avoidance, as indexed by blinking, does appear to be present at 4 months of age.
\end{abstract}

When a person perceives a rapidly approaching object, a number of defensive responses may occur: the person may blink, dodge out of its path, duck, or attempt to block the object's approach. The adaptiveness of such avoidance responses to dangerous situations is clear. The purpose of the present study is to trace the development of responses to an approaching object, and to specify the stimulus information that is effective in eliciting avoidance responses in infants. Gibson (1958) first discussed the nature of the effective visual stimulation that will elicit avoidance behavior in response to approaching objects, and hypothesized that a "family" of spatiotemporal transformations could specify direction and rate of approach and whether it is the object or the observer that is in motion.

William Schiff (1965) tested the hypothesis that the abstract visual property of accelerated magnification of a dark form in the freld of view will elicit avoidance behaviors. Using a shadow-casting device

This research was supported by a National Institute of Child Health and Human Development program project grant (HD-05027) to the University of Minnesota's Institute of Child Development, and also by grants to the University's Center for Research in Human Learning from the Institute (HD-01136) and from the National Science Foundation (GB-17590). Correspondence concerning the article and requests for reprints should be sent to Dr. Albert Yonas, Institute of Child Development, University of Minnesota, Minneapolis, Minnesota 55455. The authors wish to thank Deborah Miller for her editorial assistance. The authors also thank Gary Lamson, Patricia Aslin, and Bonita Underbakke for their help with the study. and a large rear-projection screen, Schiff found evidence for avoidance of optical expansion patterns in several nonhuman species. Although sensitivity was found in dark-reared chicks, dark-reared kittens did not reliably withdraw from the display at 26 days of age, suggesting that higher mammals may have to learn avoidance behaviors.

Research on sensitivity of human infants to information for collision has a long history. Early researchers (Gesell, 1925; Kasahara \& Inamatsu, 1931; Peiper, 1963) consistently placed the onset of blinking to the approach of a real object between the 2 nd and 4 th months of age. More recently, White (1971) did a longitudinal study of the development of blinking to an approaching object. White reported that blinking first occurred at a median age of 2 months and that by 4 months, consistent rapid blinks were evoked in almost all of the infants. White also investigated the effects of environmental enrichment on a number of responses and found that the onset of blinking is unaffected by enrichment.

Because these studies of infant responsiveness to approaching objects used real objects, we do not know which particular factors were effective in evoking defensive responses. Convergence, accommodation, and stereopsis could have specified an approaching object and evoked the blinks that were observed. In the absence of other depth information, symmetrical expansion of a form may evoke an avoidance response in infants; it is also possible that any rapid retinal motion, regardless of form, is also sufficient. Volkmann and Dodson (1976, Note 1), 
in a study of infants' responses to moving visual displays, found that the infants more frequently turned away from rapidly moving than from slower moving displays.

Jones' (1926) work supports the hypothesis that symmetrical expansion of an image is not necessary for evoking a blink when other depth information is present. The 317 infants in her study were seated on their mothers' laps while the experimenter stood behind the child and passed a hand downward about 6 in. from the infant's eyes. Jones' age norms for the development of the blinking response closely match those of White and others. However, none of these studies have determined what stimulus information is effective in eliciting the avoidance response. And, as Jones pointed out, the data does not indicate whether the response develops by maturation, by conditioning, or by some combination of the two.

In contrast to the studies discussed above, three recent reports (Ball, Note 2; Ball \& Tronick, 1971; Bower, Broughton, \& Moore, 1971) argue that sensitivity to information for collision is present in infants much younger than 2 months of age. Bower et al. discerned an avoidance response in infants as young as 6 days of age to a wide variety of approaching objects. Although blinking did not occur as part of this response, Bower et al. reported that the avoidance response does consist of three components: "(1) eyes open wide; (2) the head goes back; (3) both hands come up between object and face" (p. 193). They also reported that the approach of a real object produced "violent upset," while shadow magnification elicited a less intense response.

Ball (Note 2) and Ball and Tronick (1971) also concluded that young infants respond defensively to a symmetrically expanded shadow display and to the approach of a real object. To investigate the effect of path of approach, infants were presented with an asymmetrically expanding shadow display which they tracked to the side, but they did not respond with defensive behaviors.

These studies suggest that, while infants under 2 months of age may not blink to an approaching object, they do detect information for collision and make avoidance responses. However, except for "violent upset," the behaviors that Ball and Tronick and Bower et al. view as defensive may actually be components of tracking rather than of a defensive response, or a variation of the eye-neck reflex (Peiper, 1963) in which the head is jerked backwards by young infants to sudden illumination of the eyes. Furthermore, the evidence that young infants become violently upset when an object approaches the face is equivocal. While Bower noted that all of the five infants he tested were upset by the approach of a real object, Ball (Note 2) found that fussing at the approach of a real object was too infrequent to report in the seven infants he tested. While Bower et al. (1971) viewed eye widening as part of the avoidance response, Ball and Tronick (1971) did not observe the frequency of eye widening to an approaching object. It is clear that eye widening can occur as part of the orienting response of the young infant (Sokolov, 1963). Furthermore, the defensive character of staring wide-eyed at an object that is rapidly approaching one's eyes is questionable. Both Ball and Tronick (1971) and Bower et al. report that the infants' heads went back in response to real and optical presentations; however, they are somewhat unclear as to the form of this response. Bower et al. noted only that the eyes remained straight ahead during the response, and Ball and Tronick reported that sometimes the infants finished by facing toward the ceiling. Ball (Notes 3 and 4) does not distinguish between upward rotation and backward withdrawal of the head. It seems reasonable that the infants rotated their heads upward in response to the stimuli because they were following the movement of the upper contour of the display rather than avoiding collision. Ball raises this possibility, but discounts it. However, if it did occur, it could account for both the head response and the arm movements of the infants, since, as the head rotates backward, the infant may lose his balance and his arms may come up as part of a postural reflex. $^{1}$

The present experiments were designed to test the hypothesis that the head and arm movements of young infants reacting to an approaching object could be an aspect of tracking rather than part of a defensive avoidance response. To test this hypothesis, infants were presented in Experiment 1 with three displays using shadow projections: a symmetrically expanding display specifying collision; an asymmetrical display specifying an object on a miss path; and a nonexpanding rising contour. For the last condition, the screen was masked off into a vertical column that presented a nonexpanding contour that moved up the screen. If the responses that Ball and Tronick (1971) and Bower et al. (1971) observed were due to the infant's tracking the upper contour of the display, then expansion of the form should not be necessary to evoke these responses, and all three of the conditions should elicit the responses observed in the earlier studies.

Our purpose was to study changes with age of several responses to information for impending collision. In addition to scoring for the presence of overt behaviors, heart rate was recorded in order to index orienting and defensive autonomic responses.

\section{EXPERIMENT 1}

\section{Method}

Subjects. A total of 145 infants were involved in this study. Ninety-three infants, from 1 to 9 months of age, constituted the experimental sample. The youngest group consisted of 241 - to 2-month-old infants (12 males and 12 females; mean age = 
35 days, range $=23-47$ days). The second age group comprised 47 4- to 6-month-olds ( 24 males and 23 females; mean age = 150 days, range $=118-207$ days). The oldest group consisted of 22 8- to 9-month-old infants ( 7 males and 15 females; mean age $=$ 267 days, range $=244-297$ days). An additional 52 infants were eliminated from the study due to fussing, inattentiveness to the display, equipment failure, or expérimenter error. ${ }^{2}$ All infants were Caucasian, home-reared, and healthy. Informed consent was obtained from the parents prior to participation in the study.

Apparatus. The optical displays were presented by a shadowcaster of the type used by Ball and Tronick (1971) and Bower et al. (1971). A Sylvania C-100 concentrated arc lamp was mounted $135 \mathrm{~cm}$ behind a $1.8 \times 1.8 \mathrm{~m}$ Polocoat rear-projection screen. A $6.5 \times 6.5 \mathrm{~cm}$ opaque diamond served as the shadow-casting occluder. The diamond was supported from below by a rod on a motorized track. The extent of motion of the stimulus was $1 \mathrm{~m}$, at a constant velocity of $17.3 \mathrm{~cm} / \mathrm{sec}$. Each trial began with the diamond $33 \mathrm{~cm}$ from the screen. The diamond was then moved toward the lamp until it reached a distance of $133 \mathrm{~cm}$ from the screen, where it remained for $10 \mathrm{sec}$ before it was returned to its initial position. The luminance of the displays was $4.73 \mathrm{~cd} / \mathrm{m}^{2}$ for the shadow and $16.79 \mathrm{~cd} / \mathrm{m}^{2}$ for the background, yielding a contrast ratio of .56 , as measured from the infant's position.

The shadow of the diamond was initially presented subtending 21 visual degrees, centered on the infant's line of sight. Over a period of $5.8 \mathrm{sec}$, it expanded symmetrically until it reached a final size of 144 visual degrees. This display corresponds to an object approaching on a collision path. A display specifying a noncollision or miss path was produced by positioning the lamp $10 \mathrm{~cm}$ to the infant's right, resulting in asymmetrical expansion of the shadow. The shadow in this display appeared initially in the center of the screen and gradually moved off the left side.

The display specifying a nonexpanding rising contour was effected by lowering behind the screen a large opaque plastic sheet with a rectangular slot in the center. The slot extended from the center to the top of the screen. When the diamond was moved toward the lamp, the sheet allowed the subject to view only the apex of the diamond rising on the screen with no visible expansion.

The noise generated by the shadow-caster was masked by continuous wide-band noise from a loudspeaker located behind and at the bottom of the rear-projection screen. The intensity of the masking noise measured at the infant's position was $58 \mathrm{~dB}$ re $20 \mu \mathrm{N} / \mathrm{m}^{2}$.

Infants' behavioral responses were recorded on videotape by use of a television camera positioned approximately $45 \mathrm{deg}$ to the left of and above the infants. Sufficient light for videotaping was obtained from two small lamps positioned above and to the left of the infant.

Heart rate was continuously monitored by use of small biopotential electrodes. Output from these electrodes was fed to a Beckman Type RS Dynograph with a cardiotachometer coupler and then to a PDP computer for recording. Heart-rate data was acquired for a 10-sec period before the trial began, during the $5.8 \mathrm{sec}$ while the occluder was in motion, and for $10 \mathrm{sec}$ after the motion ceased.

Procedure. The subjects were brought individually to the laboratory by their parents. The procedure was explained and a sample trial of the display presented to the parents. When the infants was alert and content, the experimental procedure was begun.

The infant was placed on a cushioned stool centered $30 \mathrm{~cm}$ from the screen. He was held upright around the waist by an adult (usually a parent), who sat behind him, allowing the infant free movement of his arms and head. The room lights were extinguished so that all illumination was from the side spotlight and the lamp behind the projection screen.

The trials were initiated by an experimenter when the infant was judged to be alert and oriented to the display. For younger infants, responses indicating orientation included looking at the stimulus, motor quieting, eye-widening, suppression of vocalization or sucking, and postural straightening. For older infants, these behaviors were complemented by occasional vocalization and reaching toward the screen. The 1- to 2-month-old infants would usually stare at the stationary display for several seconds, which facilitated beginning the trial with the infant oriented to the display. Infants older than 2 months were more active, and trials were occasionally initiated before orienting to draw the infant's attention. At times an infant would look away from the display just as motion of the occluder began; for behavior to be scored on a given trial, the infant had to be oriented during the onset of motion, as judged from the videotaped record.

Order of presentation of the three conditions was counterbalanced across subjects. For each infant, trials were run in a condition until three oriented trials were completed, or until the infant's state was no longer acceptable. If an infant became tired or fussy, a break was taken for feeding or quieting. For an infant's data to be included in the analysis, a minimum of one scorable collision trial and one scorable trial in either the miss or the contour condition was required.

\section{Results}

The behaviors scored during the trials were blinking, upward arm movements, head rotation, head withdrawal, tracking, and fussing. ${ }^{3}$

Blinking was defined as a rapid closing of the eyelids, regardless of whether this was followed immediately by a reopening of the eyes. The presence of blinking was recorded if the infant blinked one or more times during a continuous 2-sec interval at the end of each trial, including the last second during which the diamond was in motion and the following second. The proportion of trials in which the infants blinked is shown in Table 1. For the 8- to 9-month-old infants, blinking did not occur with perfect regularity, although it was recorded on $42 \%$ of the collision trials. Often there were two or three blinks in rapid succession coupled with a wincing facial expression. Blinks were elicited significantly less frequently by the miss and contour conditions. The same patterns of results occurred with the 4- to 6month-olds; collision evoked a significantly higher proportion of trials with blinking than did the miss or contour trials. For the 1- to 2 -month-old infants, blinking was less frequent in all conditions and did not vary in frequency among the conditions.

Upward arm movement was defined as any observable movement of one or both arms toward the face, and was scored for a 3-sec interval at the end of each trial. If one hand was stationary between the face and screen throughout the trial, motion of the other arm was scored. If both arms were held up throughout the trial, no movement was recorded. The proportion of trials in which upward arm movement was present is shown in Table 1 . This response occurred most frequently in the contour condition for the 1- to 2-month-olds. However, for both the 1- to 2-month-olds and the 4- to 6-month-olds, there was no reliable difference among the three conditions for this response. For the 8- to 9-month-olds, upward arm movements did occur more frequently in the collision than in the noncollision condition. These 
Table 1

Responses of 1-9-Month Infants to Optical Displays in Experiment 1

\begin{tabular}{|c|c|c|c|c|c|c|c|c|c|c|c|c|}
\hline \multirow{2}{*}{\begin{tabular}{l}
\multicolumn{1}{c}{ Group } \\
1-2-Month Infants \\
Collision \\
Miss \\
Contour
\end{tabular}} & \multirow{2}{*}{$\frac{N}{24}$} & \multicolumn{2}{|c|}{$\begin{array}{c}\% \text { of } \\
\text { Trials with } \\
\text { Blinking }\end{array}$} & \multicolumn{2}{|c|}{$\begin{array}{l}\text { \% of } \\
\text { Trials with } \\
\text { Arms Upa }\end{array}$} & \multicolumn{2}{|c|}{$\begin{array}{c}\text { Amount of } \\
\text { Head Rotation } \\
\text { in Degreesb,c }\end{array}$} & \multicolumn{2}{|c|}{$\begin{array}{c}\text { Amount of } \\
\text { Head Withdrawal } \\
\text { in Centimeters }\end{array}$} & \multicolumn{2}{|c|}{$\begin{array}{c}\% \text { of } \\
\text { Trials with } \\
\text { Tracking }\end{array}$} & \multirow{2}{*}{$\begin{array}{c}\begin{array}{c}\% \text { of } \\
\text { Trials } \\
\text { with }\end{array} \\
\text { Fussingd }\end{array}$} \\
\hline & & $\begin{array}{l}(21)^{d} \\
(21) \\
(17)\end{array}$ & $\begin{array}{l}13 \\
07 \\
15\end{array}$ & $\begin{array}{l}(24) \\
(24) \\
(22)\end{array}$ & $\begin{array}{l}37 \\
26 \\
45\end{array}$ & $\begin{array}{l}(24) \\
(24) \\
(22)\end{array}$ & $\begin{array}{r}13.3 \\
.4 * * \\
30.1 * *\end{array}$ & $\begin{array}{l}(24) \\
(24) \\
(23)\end{array}$ & $\begin{array}{l}2.0 \\
1.5 \\
2.8\end{array}$ & $\begin{array}{l}(24) \\
(24) \\
(22)\end{array}$ & $\begin{array}{l}54 \\
90^{*} \\
74\end{array}$ & \\
\hline $\begin{array}{l}\text { 4-6-Month Infants } \\
\text { Collision } \\
\text { Miss } \\
\text { Contour }\end{array}$ & 47 & $\begin{array}{l}(47) \\
(46) \\
(35)\end{array}$ & $\begin{array}{l}20 \\
02 * * \\
08 *\end{array}$ & $\begin{array}{l}(47) \\
(46) \\
(32)\end{array}$ & $\begin{array}{l}40 \\
27 \\
31\end{array}$ & $\begin{array}{l}(47) \\
(46) \\
(34)\end{array}$ & $\begin{array}{c}6.4 \\
-7.6 \\
16.3^{* *}\end{array}$ & $\begin{array}{l}(47) \\
(46) \\
(34)\end{array}$ & $\begin{array}{r}1.1 \\
.7 \\
1.2\end{array}$ & $\begin{array}{l}(47) \\
(46) \\
(34)\end{array}$ & $\begin{array}{l}50 \\
98^{* *} \\
86^{* *}\end{array}$ & $\begin{array}{l}05 \\
02 \\
07\end{array}$ \\
\hline $\begin{array}{l}\text { 8-9-Month Infants } \\
\text { Collision } \\
\text { Miss } \\
\text { Contour }\end{array}$ & 22 & $\begin{array}{l}(22) \\
(21) \\
(17)\end{array}$ & $\begin{array}{l}42 \\
02 * * \\
16^{* *}\end{array}$ & $\begin{array}{l}(22) \\
(21) \\
(17)\end{array}$ & $\begin{array}{l}38 \\
05^{* *} \\
14\end{array}$ & $\begin{array}{l}(22) \\
(21) \\
(17)\end{array}$ & $\begin{array}{c}3.5 \\
-4.4 * * \\
30.1 * *\end{array}$ & $\begin{array}{l}(22) \\
(21) \\
(17)\end{array}$ & $\begin{array}{r}1.6 \\
.9 \\
.8\end{array}$ & $\begin{array}{l}(22) \\
(21) \\
(17)\end{array}$ & $\begin{array}{l}21 \\
98^{* *} \\
95^{* *}\end{array}$ & $\begin{array}{l}06 \\
11 \\
13\end{array}$ \\
\hline
\end{tabular}

a Significance was determined by a sign test of the difference between the collision and miss conditions and between the collision and contour conditions.

${ }^{b}$ Positive values correspond to rotation upward from the horizontal; negative values correspond to downward rotation.

CSignificance was determined by a $t$ test of the difference between means for the collision and miss conditions and for the collision and contour conditions.

d Numbers in parentheses indicate that the number of infants in each age group comprised the experimental sample for each measure. Note-Asterisks indicate that the value for the miss or contour condition was significantly different from the value of the collision condition by a one-tailed test.

$$
{ }^{*} p<.05
$$

$$
{ }^{* *} p<.01
$$

responses often appeared to be attempts to reach for the approaching object. There were several instances in which the infant began to reach, then pulled his hands back as if to protect his face when the silhouette expanded.

Rotation of the head was defined as a change in head angle along the horizontal line determined by the infant's nose and ear, from the time the infant first oriented to the display to the point of greatest rotation at the end of the trial. Upward rotation of the head is reported as positive degrees in Table 1; rotations downward are given as negative degrees. For all age groups, the collision condition evoked more rotations upward than did the miss condition. While this result replicates that of Ball and Tronick (1971), it does not provide evidence that rotation of the head is in fact an avoidance response. Indeed, for all the age groups of infants, the contour which rose on the screen without expansion evoked more rotation upward than did the collision display. This difference was significant $(p<.01)$.

While interpretation of head rotation as a defensive response is equivocal, head withdrawal more definitely suggests an adaptive avoidance response. Withdrawal from the display was assessed by measuring the largest change in head position along the median plane which occurred between the onset of and $1 \mathrm{sec}$ after the end of stimulus motion. Backward movements were scored as positive, and forward movements as negative. Measurements were recorded in centimeters of video monitor screen and then converted to centimeters of real space $(1 \mathrm{~cm}$

screen $=1.2 \mathrm{~cm}$ real space). Table 1 shows that head withdrawal was greater in the collision than in the noncollision condition for 8- to 9-month-old infants; the difference approached, but did not reach, statistical significance. In the 1- to 2-month-old and 4- to 6-month-old groups, head withdrawal was more pronounced in the collision than in the noncollision condition, but was greatest in the contour condition; however, these differences were not significant.

Tracking of the display was also recorded for each infant. Tracking was defined as a slow rotation of the head and eyes which followed the expanding contour of the display during at least half of the stimulus motion. For all age groups, tracking was significantly greater in the miss than in the collision conditions. In the 4- to 6-month-old and 8-to 9-month-old groups, tracking was also significantly greater in the contour than in the collision condition.

Infants were also observed for "fussing," to determine if the infants were more emotionally upset by the collision than by the noncollision trials. Because the incidence of either fussing or vocalizing was rare, and because it may be difficult to distinguish vocalization due to emotional distress from other sounds made by an infant, any vocalization by the infant was scored as fussing. As shown in Table 1, vocalizing in all age groups was minimal, and did not differ among the conditions.

The heart-rate data failed to show any pattern that might distinguish orienting from avoidance response. 


\section{Discussion}

The avoidance response to an optical expansion display specifying impending collision shows an extended developmental course. The data indicate that avoidance responses are absent in 1 - to 2 -monthold infants, begin to emerge in the 4- to 6-month-olds, and are present in 8- to 9-month-old infants. Our findings of slow development of avoidance responses to impending collision is consistent with reports of previous investigators concerning the gradual development of blinking to the approach of a real object (Gesell, 1925; Jones, 1926; Kasahara \& Inamatsu, 1931; White, 1971).

Of the avoidance responses recorded, only the amount of head rotation was significantly greater in the collision than in the miss condition for the 1to 2-month-old infants. The fact that head rotation was also significantly greater in the contour than in the collision condition suggests that this behavior can be more accurately attributed to tracking the contour of the display rather than to trying to avoid it. Our data suggest that the responses interpreted by Ball and Tronick (1971) and Bower et al. (1971) as integrated avoidance responses in very young infants should be interpreted more properly as instances of tracking or behavior similar to the eyeneck reflex (Peiper, 1963).

The failure to find avoidance responses in the 1to 2-month-olds could have been due to a loss of attention to the display. However, the 1- to 2-monthold infants did show the ability to differentiate among the three displays, as evidenced by significant differences found in tracking on the three conditions. Except for the severe upset reported by Bower et al. (1971) in their study involving five 8- to 17-day-old infants presented with an approaching foam rubber cube, their results also lend themselves to the interpretation that the postural changes were of an orienting nature. The infants we tested did not show signs of emotional upset in response to the displays. It seems probable that the infants tested by Bower et al. became upset during the experimental session for reasons other than fear of the stimulus. An alternative explanation for their upset is that a sudden change of head position, as might occur when tracking the upper contour of the display, may startle very young infants. Similarly, the body stiffening reported by Ball and Tronick (1971) during collision trials might be reevaluated in terms of a postural adjustment in order to maintain balance as the head goes back.

In the 4- to 6-month-old group, the infants blinked significantly more frequently in response to the collision trials than to the miss or contour conditions of avoidance. Although blinking occurred on only $20 \%$ of the collision trials, greater response might be expected to the approach of a real object.

Finally, our results indicate that avoidance clearly present in the 8- to 9-month-old infants. Blinking occurred significantly more frequently in the collision than in the noncollision or contour trials. Upward arm movement was also significantly more frequent during the collision trials. However, it should be noted that blinking occurred in only $42 \%$ of the collision trials, upward arm movement in only $38 \%$ of the trials, and amount of head withdrawal did not reach significance. In addition, fussing remained at a minimum for all conditions, as in the younger age groups. The question of whether the general patterns of avoidance would emerge earlier and more dramatically in response to a real rather than an optical stimulus was explored in Experiment 3.

\section{EXPERIMENT 2}

The purpose of this study was to investigate whether the head rotation observed in young infants in response to a looming display was a result of tracking the contour of the display or of avoiding the display. Experiment 2 involved presentation of an optical expansion pattern, the top contour of which stayed at eye level throughout the trial. If upward rotation of the head occurs when the contour does not rise in the display, rotation of the head could then be interpreted as an avoidance response. If no head rotation is observed, it would suggest that the rotation response observed in Experiment 1 resulted from the infant following the upper contour of the display.

This experiment was also intended to clarify the relationship between the magnitude of the avoidance response and the rate of approach specified by the looming display. Bower et al. (1971) reported that the magnitude of the response was an inverse function of the rate of approach. Bower (1966) speculated that the infant's visual system was influenced by a limited "data rate" which restricted his ability to visually detect a rapidly approaching object. It might be argued, therefore, that the 1- and 2-month-old infants in Experiment 1 failed to respond to impending collision because the information in the looming display was presented too rapidly to be processed by the infants. To determine if speed of approach could account for the lack of avoidance in Experiment 1, the stimulus in the present study was moved at 7 to $8 \mathrm{~cm} / \mathrm{sec}$, which is near the optimum speed reported by Bower et al. (1971) and is $2 \frac{1 / 4}{4}$ times slower than the rate of approach used in Experiment 1.

\footnotetext{
Method

Subjects. A total of 18 infants ( 9 males, 9 females; mean age $=$ 41.4 days, range $=28-57$ days) constituted the experimental sample. All were Caucasian, home-reared, and healthy. Informed consent was obtained prior to participation. Data from an additional
} 
14 infants was not used due to equipment failure, experimental error, or problems with their state.

Apparatus. The apparatus was the same as that used in Experiment 1, with the following changes: The shadow-casting occluder was an inverted triangle of red translucent plastic, $7 \times 10 \times 7 \mathrm{~cm}$. The top contour of the displays remained at eye level. In collision trials, the stimulus initially subtended $30 \mathrm{deg}$ of visual angle, expanding to $144 \mathrm{deg}$ at the end of the trial and filling the lower half of the screen. On noncollission trials, the lamp of the shadow-caster was displaced $10 \mathrm{~cm}$ to the infant's right, to create an asymmetrical expansion pattern on the lower half of the screen which disappeared off the left edge of the screen. The luminance of the screen was $86.16 \mathrm{~cd} / \mathrm{m}^{2}$, thus yielding a contrast ratio of .67 .

Procedure. Procedures in Experiment 2 were the same as those in Experiment 1 with the following exceptions: no heart-rate data were collected; only collision and noncollision conditions were used; and the rate of approach used was 7 to $8 \mathrm{~cm} / \mathrm{sec}$. Trial length was 15 to $17 \mathrm{sec}$ for $1 \mathrm{~m}$ of occluder motion.

\section{Results}

Table 2 summarizes the data collected from this experiment. Measures were made of blinking, arm movement, head rotation, head withdrawal, tracking, and emotional upset, as in Experiment 1. Differences in tracking between collision and noncollision conditions were significant by a sign test. The $t$ tests of differences between collision and noncollision conditions for head withdrawal and head rotation were nonsignificant. Sign tests revealed no significant differences between conditions for blinking, arm movements, and fussing.

\section{Discussion}

The results of this experiment suggest that the "head back" response to information for impending collision observed in very young infants by Ball and Tronick (1971) and Bower et al. (1971) and the backward head rotation observed in Experiment 1 were not avoidance responses, but were instead orienting responses in tracking a rising contour. Although we presented no rising contours, expansion information for impending collision was present, yet no significant difference in head rotation between collision and noncollision conditions was observed. In fact, no upward rotation or backward withdrawal of the head was observed in either condition. Furthermore, no differences were found in the amount of blinking or the incidence of upward arm movement. Fussing was also almost nonexistent in both conditions. The only difference between the two conditions that was significant was a greater amount of tracking on the noncollision trials than on the collision trials. We may assume, therefore, that the infants in this study were tracking or staring at the stimulus rather than attempting to avoid it.

In addition, despite the fact that the speed of approach used was in the range considered optimally effective by Bower et al. (1971), no avoidance behavior was observed in this experiment. We also found no evidence of avoidance with the 1-month-old infants in Experiment 1, in which a looming speed $21 / 4$ times faster was used. Schiff (1965) reported that avoidance occurred in response to both relatively slow and fast looming speeds, although he did note that the rapidly approaching object evoked an avoidance response with shorter latency in the species that he studied. Regardless of the rate of the looming speed, the animals ducked at the time of collision. Although we have no evidence to support Bower's contention that a slowly approaching object is more effective in eliciting an avoidance response in very young infants, we do not know the effect the rate of approach would have on the avoidance behavior of older infants.

\section{EXPERIMENT 3}

While Ball and Tronick (1971) found an optical expansion pattern to be as effective as the approach of a real object in eliciting avoidance behavior, Bower et al. (1971) report that the approach of a real object produces an avoidance response of much greater magnitude. The approach of a real object is the most robust situation for eliciting avoidance, because the approach is specified by redundant information. In addition to optical expansion information, the approach of a real object is specified by

Table 2

Responses of 1-2-Month Infants to Optical Displays in Experiment 2

\begin{tabular}{|c|c|c|c|c|c|c|c|}
\hline Condition & $\mathrm{N}$ & $\begin{array}{l}\% \text { of } \\
\text { Trials with } \\
\text { Blinking }\end{array}$ & $\begin{array}{l}\text { \% of } \\
\text { Trials with } \\
\text { Arms Up }\end{array}$ & $\begin{array}{c}\text { Amount of } \\
\text { Head Rotation } \\
\text { in } \\
\text { Degrees }^{b}, \mathbf{c}\end{array}$ & $\begin{array}{c}\text { Amount of } \\
\text { Head } \\
\text { Withdrawal in } \\
\text { Centimeters } \\
\end{array}$ & $\begin{array}{l}\text { \% of } \\
\text { Trials with } \\
\text { Tracking }\end{array}$ & $\begin{array}{c}\% \text { of } \\
\text { Trials with } \\
\text { Fussing }\end{array}$ \\
\hline $\begin{array}{l}\text { Collision } \\
\text { Miss }\end{array}$ & $\begin{array}{l}18 \\
18\end{array}$ & $\begin{array}{l}14 \\
27\end{array}$ & $\begin{array}{l}51 \\
57\end{array}$ & $\begin{array}{l}-2.5 \\
-4.4\end{array}$ & $\begin{array}{r}-.4 \\
-1.0\end{array}$ & $\begin{array}{c}45 \\
100^{* *}\end{array}$ & $\begin{array}{l}02 \\
09\end{array}$ \\
\hline
\end{tabular}

a Significance was determined by a sign test of the difference between the collision and miss conditions.

bositive values correspond to rotation upward from the horizontal; negative values correspond to downward rotation.

cSignificance was determined by a t test of the difference between means for the collision and miss conditions and for the collision and contour conditions.

Note-Asterisks indicate that the value for the miss or contour condition was significantly different from the value of the collision condition by a one-tailed test. 
motion parallex, progressive background occlusion, and air pressure gradients. Accommodation, convergence, and binocular disparity may provide additional information. The results obtained by Bower et al. (1971) suggest that the lack of avoidance observed in Experiments 1 and 2 may have been due to impoverished stimulus information. If sensitivity to information for impending collision is present in young infants, it is most likely to be demonstrated with an approaching real object. In this experiment, 1- to 2-month-olds were presented with real objects that approached on collision and noncollision courses.

\section{Method}

Subjects. Sixty infants participated in this study. The experimental sample comprised 28 infants of 1 to 2 months of age ( 16 males and 12 females; mean age $=34$ days, range $=24$ 25 days). All infants were Caucasian, home-reared, and healthy. Informed consent was obtained prior to participation. An additional 32 infants were eliminated from the study due to sleepiness, fussiness, equipment failure, or experimenter error.

Apparatus. The shadow-casting apparatus, described in Experiment 1, was modified to present the infants with a real object which approached on a collision or a noncollision course. The rear-projection screen and point-source lamp were removed, and a partial enclosure was constructed by hanging off-white drapery fabric on three sides of the motorized track. The shadowcasting occluder was replaced by a Styrofoam square, $28 \times 28 \times$ $3.2 \mathrm{~cm}$, covered with black construction paper. Each infant was positioned so that his line of sight intersected the center of the object. The object moved from an initial position $115 \mathrm{~cm}$ from the infant to a terminal position $15 \mathrm{~cm}$ from the infant. After remaining in the position nearest the infant for $10 \mathrm{sec}$, the object was returned to its initial position. The object moved toward the infant at a constant rate of $18.2 \mathrm{~cm} / \mathrm{sec}$. The display was illuminated from above by two fluorescent tubes. The luminance of the object at its initial position was $9.01 \mathrm{~cd} / \mathrm{m}^{2}$; the luminance at the terminal position was $.55 \mathrm{~cd} / \mathrm{m}^{2}$. Contrast thus varied from .82 to .88 . Measurements were made from the infant's position. A masking noise was employed, as in Experiment 1.

A collision display was presented by operating the apparatus with the infant in position at the end of, and in line with, the linear motion of the object. The infant was initially presented with a diamond-shaped closed contour, 20 visual degrees in size and centered on his line of sight, which underwent symmetrical expansion oyer a period of $5.5 \mathrm{sec}$ to reach a final size of 106 visual degrees. The noncollision display was effected by displacing the infant $50 \mathrm{~cm}$ to his right, resulting in asymmetrical leftward expansion of the object. We therefore provided essentially the same displays in Experiments 1 and 3, so as to make feasible comparisons between data. However, we did not present a real object correlate of the contour condition used in Experiment 1.

The infants' behavioral responses to the stimulus displays were recorded on videotape, as in Experiment 1. However, two cameras were used in this procedure, one at $\mathbf{9 0}$ deg to the infant's line of sight and to his left, and the other above and approximately $30 \mathrm{deg}$ to the infant's right. A mirror was positioned to provide a reflected image of the stimulus displays. The output from the cameras was mixed by use of a special effects generator to provide a split-screen image to a videotape recorder and television monitor in the adjoining control room.

Procedure. The procedures used in Experiment 3 were the same as those used in Experiment 1, except for the following changes: For the collision condition, the stool on which the infant sat was centered in front of the stimulus, $6 \mathrm{in}$. from the end of the track. To create the miss condition, the stool was moved to $20 \mathrm{in}$. $(50.8 \mathrm{~cm})$ right of center, so that the object veered off to the infant's left side. Overhead room lights remained on throughout the procedure. Because the object was initially positioned quite a distance from the infant, trials were begun to draw the infant's attention to the object. The motion of the object lasted $5.5 \mathrm{sec}$. Heart rate was again recorded for the trial period and for pre- and posttrial periods of $10 \mathrm{sec}$ each. The grid used on the monitor for scoring head movement was the same as that used in Experiment 1. The units corresponded to $1.1 \mathrm{~cm}$ of real space in the collision condition and to $.96 \mathrm{~cm}$ in the noncollision condition.

\section{Results}

Data from Experiment 3 are summarized in Table 3. Behavioral measures in this experiment were scored as in the previous experiments. Sign test comparisons of differences between the collision and noncollision conditions were not significant for either blinking or upward arm movement. The $t$ tests of the differences between means of the collision and noncollision conditions were nonsignificant for the head-rotation and head-withdrawal measures. A sign test comparison showed significantly more tracking of the noncollision display. Fussing occurred rarely and did not vary significantly between conditions.

Table 3

Responses of 1-2-Month Infants to Real Object in Experiment 3

\begin{tabular}{lccccccc}
\hline Condition & N & $\begin{array}{c}\text { \% of } \\
\text { Trials with } \\
\text { Blinking }^{\mathbf{a}}\end{array}$ & $\begin{array}{c}\text { \% of } \\
\text { Trials with } \\
\text { Arms Up }^{\mathbf{a}}\end{array}$ & $\begin{array}{c}\text { Amount of } \\
\text { Head Rotation } \\
\text { in } \\
\text { Degrees }^{\mathbf{b}, \mathbf{c}}\end{array}$ & $\begin{array}{c}\text { Amount of } \\
\text { Head } \\
\text { Withdrawal in } \\
\text { Centimeters }^{\mathbf{c}}\end{array}$ & $\begin{array}{c}\text { \% of } \\
\text { Trials with } \\
\text { Tracking }^{\mathrm{a}}\end{array}$ & $\begin{array}{c}\% \text { of } \\
\text { Trials with } \\
\text { Fussing }^{\mathbf{a}}\end{array}$ \\
\hline Collision & 28 & 04 & 26 & 4.0 & 1.2 & 41 & 01 \\
Miss & 28 & 05 & 19 & 4.1 & .7 & $96^{*}$ & 05 \\
\hline
\end{tabular}

a Significance was determined by a sign test of the difference between the collision and miss conditions.

b Positive values correspond to rotation upward from the horizontal; negative values correspond to downward rotation.

cSignificance was determined by a t test of the difference between means for the collision and miss conditions and for the collision and contour conditions.

Note-Asterisks indicate that the value for the miss or contour condition was significantly different from the value of the collision condition by a one-tailed test. 


\section{Discussion}

The 1- to 2-month-old infants exhibited no avoidance behavior in response to the approach of a real object. The only behavior that differentiated between the collision and noncollision conditions was tracking, with more tracking of the noncollision than of the collision display. This finding does not support the contention by Ball and Tronick (1971) and Bower et al. (1971) that young infants are sensitive to information for impending collision.

However, in a pilot study, 10 4- to 6-month-olds did respond appropriately to the approach of the real object. The infants in this age group typically reached for the approaching object and grasped it as soon as it was within reach.

The results of the testing of 1- to 2-month-olds, although inconsistent with recent reports, are in agreement with the earlier data on the development of the blink reflex in response to the approach of a real object (Gesell, 1925; Kasahara \& Inamatsu, 1931; White, 1971). Research in progress involves investigating the responsiveness to impending collision for the 2- to 4-month age group, not included in this study.

\section{GENERAL DISCUSSION}

The results of the present experiments fail to replicate the findings by Ball and Tronick (1971) and Bower et al. (1971) that infants under 1 month of age are sensitive to information for impending collision and respond with appropriate defensive or avoidance behaviors. Analysis of data from Experiment 1 indicates that behaviors previously interpreted as defensive may more properly be interpreted as visual tracking of a contour, an effort by the infant to keep certain parts of the stimulus array in view. Behavior suggestive of a defensive response and not attributable to tracking, that is, blinking at impact, was absent in 1- and 2-month-old infants and present in 4-month-old infants. The complex of defensive behaviors in response to an approaching object appears to undergo a rather extended development, with an integrated defensive response first appearing at approximately 8 months of age.

The results of Experiments 2 and 3 provide evidence that the failure of 1- to 2-month-old infants to respond defensively to the displays in Experiment 1 is not attributable to either the impoverishment of the shadow stimulus relative to a real object or the "data rate" demands imposed by the rapid speed of object approach. Neither a slower expanding shadow nor an approaching real object elicited defensive behaviors from these very young infants. In addition, the absence of backward rotation of the head in response to the expansion display without contour elevation lends further support to the contention that previously reported avoidance behaviors in the youngest age range are actually tracking responses.

\section{REFERENCE NOTES}

1. Volkmann, F. C. Personal communication, May 28, 1976.

2. Ball. W. A. Intant responses to looming objects and shadow's. Unpublished honors thesis, Harvard University. 1970.

3. Ball, W. A. Personal communication, March 16, 1976.

4. Ball, W. A. A developmental perspective on percetved movement in depth. Paper presented at the meeting of the International Congress of Psychology. Paris, July 1976.

\section{REFERENCES}

Ball. W. A. \& Tronick, E. Intant responses to impending collisions: Optical and real. Science, 1971, 171, 818-820.

Bower, T. G. R. The visual world of intants. Scientific American, 1966, 215, 80-92.

Bower, T. G. R., Broughton. J. M., \& Moore, M. K. Infant responses to approaching objects: An indicator of response to distal variables. Perception \& Psychophysics, 1971, 9. 193-196.

GeselL. R. Mental grow'th of the pre-school child. New York: Macmillan, 1925.

Gibson, J. J, Visually controlled locomotion and visual orientation in animals. British Jowmal of Psychology, 1958, 49, 182-194.

Jones. M. C. The development of early behavior patterns in young chiddren. The Pedagogical Semimury and Journal of Genetic Psychology. 1926, 33, 537-585.

Kasahara, M.. \& Inamatsu, S. Der Blinzelreflex im Sauglingsalter. Archiv Fur Kinderheilkunder, 1931. 92. 302-304.

PEIPER. A. M. D. Cerebral function in intancy and childhood. New York: Consultants Bureau, 1963.

Schiff, W. The perception of impending collision: A study of visually directed avoidant behavior. Psychological Monographs. 1965, 79(Whole No. 604)

Sokolov. Y. N. Perception and the conditioned reflex. New York: Macmillan, 1963.

VolkmanN, F, C., \& Dobson, M. V. Intant responses of ocular fixation to moving visual stimuli. Joumal of Experimental Child Psychology, 1976. 21, in press.

White, 8. L. Humant injants experience and psvchological development. Englewood Clifts. N.J: Prentice-Hall, 1971

\section{NOTES}

1. The male pronoun is used in its generic sense.

2. In Experiment 1, 52 infants were eliminated from the three age groups as follows: 201 - to 2-month-olds (18 sleepy, fussy, or inattentive to the stimulus displays and 2 due to equipment failure or experimenter error), 24 4- to 6-month-olds (21 due to problems with their state and 3 due to equipment failure or experimenter error), and 88 - to 9-month-olds (6 due to state problems and 2 due to equipment failure or experimenter error).

3. Blinking, upward arm movement, and tracking were scored by three independent observers from the video tape record. Although each observer was responsible for scoring one-third of the trials, a number of trials were scored by all three observers. The proportion of judgments in which there was agreement between the three observers was .91 .

(Received for publication August 2, 1976; revision accepted November $4,1976$. 